\title{
A Inteligência Competitiva modelando o Sistema de Informação de Clientes - Finep*
}

\section{Maria da Glória Botelho Battaglia}

\begin{abstract}
Resumo
A Finep, cuja missão é "fazer da ciência e tecnologia instrumentos para construir o futuro do Brasil », necessita hoje de um sistema de informação modelado para atender, ao mesmo tempo, os clientes que buscam financiamento e a sociedade/ comunidade de C\&T, enquanto atores do desenvolvimento, de onde novas demandas de financiamento são apresentadas. Este estudo propõe um sistema de informação de clientes pautado nos componentes da inteligência competitiva, para que a empresa Finep desempenhe, cada vez melhor, a sua missão de apoio financeiro à área de C\&T, orientando as próprias demandas com base no movimento dos diversos setores inseridos nesse mundo globalizado e gerenciando melhor suas operações contratadas. O Sistema de Informação de Cliente para a Finep, uma vez em funcionamento, constituir-se-á também em suporte para a estruturação de uma unidade de inteligência competitiva, a fim de apoiá-la nas ações inerentes à execução de seu negócio, dos planos de negócio de suas unidades e na sustentação de suas vantagens competitivas.
\end{abstract}

\section{Palavras-chave}

Financiadora de Estudos e Projetos (Finep); Sistema de Informação; Sistema de Informação de Clientes; Inteligência Competitiva; Clientes-Finep.

\section{INTRODUÇÃO}

A Financiadora de Estudos e Projetos (Finep) é uma empresa pública, vinculada ao Ministério de Ciência e Tecnologia, criada com o objetivo de fomentar técnica e financeiramente estudos, pesquisas, projetos e programas de importância para o desenvolvimento científico e tecnológico do país, de acordo com as metas e prioridades setoriais fixadas pelo governo federal. É o principal órgão responsável pela seleção, análise e financiamento de projetos na área de inovação industrial, ciência e tecnologia, desde a fase de pesquisa básica até a etapa de industrialização e comercialização. Pela natureza de suas atividades, a Finep acumula informações relevantes em C\&T contidas em documentos que caracterizam suas operações de financiamento de projetos: trata-se de informações tanto científicas, quanto tecnológicas e industriais, geradas pelos seus clientes.

"Este artigo foi extraído da monografia elaborada para obtenção do DEA - Diplome d'Etudes Approfondies pela Universidade de Marseille III em Inteligência Competitiva e teve a orientação dos professores:

Lena Vania Ribeiro Pinheiro, doutora em Comunicação e Cultura, mestre em Ciência da Informação, prof. do Curso de Pós-graduação em Ciência da Informação da Escola de Comunicação da UFRJ e chefe do Departamento de Ensino e Pesquisa do Instituto Brasileiro de Informação em Ciência e Tecnologia IBICT e Maria Fátima Stollenwerk, mestre em Gestão Tecnológica e DEA em Ciência da Informação e Comunicação e técnica da Petrobrás. M. Henri Dou Professeur Directeur du CRRM - Université Aix - Marseille III e M. Luc Quoniam Maître de Conférence, CRRM - Université Aix - Marseille III
Os clientes da Finep são clientes especiais, porque estão ligados diretamente ao desenvolvimento científico, tecnológico e industrial do país e inserem-se no macroambiente, isto é, governo, empresas, universidades e a sociedade. A relação Finep-cliente é o próprio movimento do desenvolvimento científico e tecnológico, explicitado por meio da informação. A relação com os clientes é de importância capital para a Finep, sendo, portanto, necessário melhorá-la em face das exigências da globalização.

O objetivo maior deste estudo é a proposta de construção de um modelo de Sistema de Informação de Clientes da Finep, a partir dos elementos da inteligência competitiva. Além da grande mudança que a nova estrutura de dados vai trazer na relação com os clientes, alguns benefícios serão alcançados de imediato e ao mesmo tempo será possível também tornar disponíveis, para a comunidade de C\&T, informações sobre as instituições e empresas clientes da Finep, além, naturalmente, de aumentar o grau de informações da Finep sobre o potencial de seus clientes e a possibilidade de acompanhar o movimento dos diversos setores econômicos e, ao mesmo tempo, oferecer estas informações nos vários níveis para a tomada de decisão. 


\section{INFORMACÃO: CHAVE PARA O DESENVOLVIMENTO DA INTELIGÊNCIA COMPETITIVA}

A inteligência competitiva é fundamentada em duas grandes bases: a informação e a velocidade de seu uso. Estes dois componentes são chave para o entendimento da inteligência competitiva, pela simples razão de que a inteligência competitiva faz uso de tipos e fontes diversas de informações em uma velocidade muito grande para monitorar desenvolvimentos de produtos, processos, serviços e posições de mercado. Na realidade, a velocidade é o grande desafio, porque mais que o desenvolvimento tecnológico, o marco fundamental do século XX é a velocidade com que as mudanças acontecem, e a inteligência competitiva tem a função de monitorar estas mudanças para que as empresas mantenham seu posicionamento e se tornem cada vez mais competitivas no mercado global. No entanto, é necessário conhecer bem os tipos e fontes de informação, seus conceitos e onde são gerados, e é na ciência da informação que vamos encontrá-los.

A ciência da informação é a disciplina que faz da INFORMAÇÃO o seu objeto de estudo, considerando a sua produção, análise, transferência e absorção. Portanto, é da ciência da informação que vamos derivar os conceitos que explicitem o que é "informação" e quais as suas formas de abordagem. Segundo Lena Vania Pinheiro, podemos considerar a INFORMAÇÃO como objeto de estudo complexo e intangível, produzido e absorvido pelo homem, em um ciclo também complexo, uma vez que envolve o processo cognitivo (1). E a partir deste contexto que podemos arrolar alguns conceitos de informação, especialmente aqueles ligados ao desenvolvimento científico e tecnológico. A Informação em C\&T na definição da Unisist II, conferência promovida pela Unesco, "é constituída de elementos simbólicos utilizados para comunicar o conhecimento científico e técnico, independente de seu caráter (numérico, textual, icônico etc.), dos suportes materiais e da forma de apresentação². Mautort considera a informação insumo para o desenvolvimento científico e tecnológico e adota a seguinte definição: "informação científica e tec- nológica é o insumo para atividades de pesquisa científica e tecnológica e para a aplicação em desenvolvimento econômico e industrial "3. Para aprofundar os conceitos "científico" e "tecnológico" e sua contribuição em ICT, analisamos cada um de per si, associando-os ao conceito de informação. Ciência é considerada por Longo como "um conjunto organizado dos conhecimentos relativos ao universo, envolvendo seus fenômenos naturais, ambientais e comportamentais" 4 . A geração do conhecimento científico se faz por meio da pesquisa ou investigação científica, seguindo as etapas do método ou metodologia científica. Ainda o mesmo autor define tecnologia como o conjunto organizado de todos os conhecimentos científicos, empíricos ou intuitivos, empregados na produção e comercialização de bens e serviços ${ }^{4}$ - A estreita ligação entre ciência e tecnologia fez surgir o binômio Ciência e Tecnologia (C\&T) e a forma de se comunicar estes conhecimentos é por meio da informação. Dentro desse enfoque, e com base no conceito de Aguiar, informação científica, por sua vez, é a expressão de todo o conhecimento que envolve a pesquisa básica, aplicada e o desenvolvimento experimental, objetivando o reconhecimento pela comunidade que os criou, a divulgação do novo conhecimento obtido e a propriedade intelectual do pesquisador ${ }^{2}$. A informação científica é gerada no meio acadêmico e se insere no ciclo pelo qual o pesquisador produz conhecimento, comunica-o a seus pares informal e formalmente, consome conhecimento e volta a produzir novo conhecimento, em um ciclo de autoalimentação. Portanto, o cientista gera e consome conhecimento. O produto da ciência é basicamente um novo conhecimento, que é repassado por meio da informação, tendo como suporte o documento ${ }^{5}$.

O domínio público da literatura científica faz parte do processo de comunicação científica, sua atividade mais importante é a avaliação da produção científica feita pelos pares, pelos referees, cujo resultado é determinante para que a publicação ocorra e conseqüentemente para o seu reconhecimento. O cientista vive, por essas razões, em torno de suas publicações e um dos veículos usados para disseminá- las é a revista científica, ou seja, o periódico. Nesse contexto, o periódico científico é o meio de comunicação formal mais importante, porque registra e divulga a produção científica.

O ciclo de informação na área tecnológica é diferente. O segredo é fundamental para o seu desenvolvimento e para protegê-la existem as patentes, cujo sistema é estruturado com informações tecnológicas das mais relevantes possíveis, favorecendo o país proprietário da tecnologia.

Tecnologia é, em síntese, definida por Longo como um conjunto ordenado de conhecimento, e a sua transferência é entendida como a capacidade de domínio e uso desses mesmos conhecimentos, por outros países que não só o detentor da tecnologia. Por analogia, a transferência de informação é a transferência, de um país a outro, de informação registrada em algum tipo de suporte material, em qualquer área. Assim, a informação é um componente fundamental para que a transferência de tecnologia e da própria ciência aconteça. Miranda considera que estamos em um mundo de países produtores e exportadores de informação e de países importadores, com baixo poder aquisitivo e com baixa capacidade de consumo, muitas vezes obrigados a importar base de dados ou coleções de documentos sem real utilidade $^{6}$. O mesmo raciocínio é expresso por Menou, quando afirma que "os países desenvolvidos ditam as diretrizes e subordinam, consciente ou inconscientemente, pelo poder da sua posição monolítica, a produção de conhecimento e de informação, de acordo com seus interesses"7.

A informação tem, portanto, poder de dominação e é capaz de ditar regras que sejam de interesse dos países desenvolvidos para manter posição de mercado e garantir vantagem competitiva, a qual está ligada ao esforço contínuo de atualização, cuja atividade de monitoramento torna-se imprescindível. Segundo Figueredo, o problema se torna muito mais complexo quando a transferência de informação é considerada como transferência de tecnologia ${ }^{8}$. Dentro desta ótica, Miranda considera transferência de tecnologia e de informação termos xipófagos, complemen- 
tares, indissociáveis ${ }^{6}$. Como no processo de transferência de tecnologia também a transferência de informação está ligada à especificação de uma demanda, detalhada por quem vai usá-la e é no momento do uso que lhe vai ser atribuído um valor. Pierson tem isto muito claro, quando afirma que as necessidades são determinantes para o uso, e conseqüentemente o valor da informação sofre influência do próprio demandante que pode ser o pesquisador, o grupo ao qual pertence e a instituição na qual está inserido. O autor afirma, ainda, que a informação não tem um valor absoluto, mas sim um valor que é dependente do tempo em que chega ao usuário(9). Para Menou, o conceito de transferência de informação está diretamente relacionado à adequabilidade da informação. Neste sentido, a informação segue os mesmos passos e as mesmas exigências da própria transferência de tecnologia. Ela deve ser apropriada e para isto, a informação para ser considerada apropriada para um país, para um pesquisador ou para um usuário comum deve ser a expressão de uma demanda, que satisfaça às suas próprias necessidades, tradições, condições materiais e padrões culturais ${ }^{(7)}$. Uma das razões para que a informação deva ser adequada é o fato de que a sua vida útil é curta, em face da aceleração do processo de inovação e mudança instalado, rapidamente entra no processo de obsolescência. Ao mesmo tempo, o não conhecimento do que já é passado impede a compreensão do contexto e das tendências futuras, além de ser a base para o avanço científico e tecnológico. A informação tem, portanto, o momento certo para sua existência, para sua aplicação e para o seu uso. Se não for utilizada no momento certo, pode se tornar obsoleta e perde o seu valor. $O$ estudo de citação determina a curva de vida de uma informação. A sua idade é fundamental para o seu uso. Quanto mais nova, mais útil será, mais valor terá.

A capacidade de gerar e de absorver informação - conhecimento - é medida para se avaliar o desenvolvimento de um país. Neste contexto, Borko afirma que a "informação é um meio pelo qual uma nação em desenvolvimento pode aumentar o seu produto nacional bruto, elevar o padrão de vida de seus cidadãos e reduzir a distância entre as nações dos que têm e as que não têm"10. No entanto, a transferência de informação por si só, não assegura a transferência de tecnologia, e Longo afirma que "o termo transferência de tecnologia" não expressa o que ocorre no processo. O uso da palavra transferência, e não compra, dá idéia de que o cedente está realizando uma ação altruística, fornecendo ao receptor todos os conhecimentos que possui sobre determinado assunto, para ajudálo a resolver um problema. Na verdade, o que ocorre é uma venda, na qual, quase sempre, o vendedor esconde os conhecimentos e vende as instruções ${ }^{11}$. Nos países em desenvolvimento, o termo "transferência de tecnologia" refere-se mais ao processo de importação de tecnologia. O proprietário da tecnologia é protegido por um monopólio legal, por meio do sistema de patentes. A transferência de tecnologia só acontece quando no processo os pré-requisitos necessários são estabelecidos e respeitados, ou seja : motivação para que seja de fato transferida; recursos financeiros suficientes para assegurar a viabilidade do projeto; recursos humanos adequados (mão-de-obra que garanta habilidades técnicas, gerenciais e de produção). Sem estes fatores, não há transferência de tecnologia, ou ela é incompleta ou é imprópria $^{12}$. A solução seria conhecer, dominar, absorver e utilizar e/ou adaptar as tecnologias já disponíveis, para reduzir o atraso tecnológico. O monitoramento da evolução tecnológica e do progresso científico é fundamental neste processo. E, para que este acompanhamento tenha sucesso, a informação organizada, analisada e automatizada tem um papel relevante neste contexto. O conceito de tecnologia apropriada se relaciona com a infraestrutura de um país, com as necessidades de seus usuários e com o meio ambiente onde ela flui e que, dependendo dos objetivos, características, atuação, dá a ela funções específicas ${ }^{12}$.

$\mathrm{Na}$ área tecnológica, o produto final não é o conhecimento sob a forma de documento publicado ou não, e sim a própria tecnologia (incluindo o método, processo, equipamentos, dispositivos, ou seja, o PRODUTO) industrializável e comercializável. Seu desenvolvimento envolve diretamente a produção de bens, o invento, a inovação, está, portanto, voltada para o desenvolvimento econômico. A experiência de trabalho na Finep mostrou que o ciclo de informação tecnológica é mais complexo, porque envolve sigilo e restrições, sendo inclusive condições expressas nas cláusulas contratuais. Evidentemente, o acesso é mais difícil, apesar de ser de suma importância, porque a informação tecnológica, seja a recente, seja a retrospectiva, é o insumo necessário ao desenvolvimento.

O sistema de propriedade industrial assegura não só o sigilo e as restrições sobre a tecnologia, como permite também que as informações possam ser usadas livremente, de forma a subsidiar novas pesquisas. Depois que passa o tempo estabelecido pelo depósito legal, então a informação passa a ser disponibilizada nos sistemas de informações de patentes, nos órgãos oficiais de propriedade industrial e em escritórios especializados. A patente se inclui entre os direitos de propriedade industrial e pode ser definida como: "Um privilégio temporário que o Estado concede à pessoa - física ou jurídica - pela criação de algo novo, com aplicação industrial, suscetível de beneficiar a sociedade", ao mesmo tempo, protege o titular e lhe confere o direito de impedir que terceiros, que não tenham a sua licença, possam produzir, usar, colocar a venda, vender, importar o produto ou processo objeto da patente ${ }^{13}$. Para a Organização Mundial de Propriedade Industrial (Ompi), a patente é um documento expedido por um órgão governamental, que descreve a invenção e cria uma situação legal, na qual a invenção patenteada pode normalmente ser explorada (fabricada, importada, vendida e usada) com autorização do titular. A característica principal do documento de patente é o requisito de patenteabilidade, o que significa que só é patenteável a invenção que atenda aos requisitos de novidade, isto é, que não tenha sido divulgada antes, que seja inédita, portanto que não tenha existido ainda, que possua atividade inventiva e aplicação industrial, passível, portanto, de ser comercializada ${ }^{14}$. A invenção é considerada nova quando não está inserida no estado da técnica, e este é constituído por todo o registro de acesso público antes da data de depósito do pedido 
de patente, por descrição escrita ou oral, por uso ou qualquer outro meio, no país de origem ou no exterior.

O documento patente é tão importante, que o seu conteúdo informacional está estruturado em três níveis. O primeiro nível diz respeito aos dados de identificação, que correspondem às informações sobre país de prioridade, países de depósito, países designados, número de publicação, data de prioridade, nome do inventor, empresa depositante, título da invenção, códigos da CIP (Classificação Internacional de Patentes), natureza do documento. O segundo nível, retrata, por meio de resumos, o conteúdo informacional técnico das patentes. Normalmente estes são elaborados, divulgados e disseminados com bastante atraso, impedindo que a informação de patentes circule com mais rapidez e responda com mais precisão às exigências de relevância e pertinência. O terceiro nível é a informação completa, o documento inteiro, os textos completos. Estes, normalmente, são disponibilizados pelos organismos oficiais de propriedade industrial ou escritórios especializa$\operatorname{dos}^{13}$.

Nas bases de dados, o conteúdo informacional das patentes toma a forma de referência bibliográfica, altamente padronizada, com ferramenta de recuperação própria e utilizada por todos os países signatários da Organização Mundial da Propriedade Industrial (Ompi), que é a Classificação Internacional de Patentes. Por esta razão, as bases de dados internacionais de patentes são de grande importância para o monitoramento tecnológico e vantagem competitiva. É uma das principais fontes de informação estratégica utilizadas pela Inteligência Competitiva. É importante salientar, que, além das patentes, informações sobre inovações, contratos de transferência de tecnologia, descrição de produtos e processos são considerados informações tecnológicas por excelência. $O$ relatório técnico e a carta-patente são considerados documentos-chave na área tecnológica, outros, como normas técnicas, catálogos de equipamentos, especificações são também de importância capital, porque, quando falamos em tecnologia associada ao processo de aperfeiçoamento e inovação, pen- samos na industrialização e nos tipos de informação que uma indústria necessita para o seu desenvolvimento. A informação tecnológica é, portanto, orientadora da produção, mais do que isto, ela gera novas informações, completando o ciclo de retroalimentação.

A Federação Internacional de Documentação (FID), define Informação Tecnológica como "todo o conhecimento de natureza técnica, econômica, mercadológica, social etc., que, por sua aplicação, favoreça o progresso na forma de aperfeiçoamento e inovação"15. O conceito da FID trata de todo tipo de informação ligada ao desenvolvimento industrial, econômico e social, no que diz respeito tanto a uma empresa em particular, quanto a uma nação. No entanto, a abrangência deste conceito impede que se consiga reunir numa só base de dados todas as informações necessárias para que possa cumprir integralmente a sua função: a de prestar informação tecnológica aos usuários-alvo.

O ciclo da informação tecnológica é diferente da área científica, tem dinamismo próprio, especialmente porque visa a uma aplicação industrial. Requer, portanto, capital para investimento e, como conseqüência, a exigência de um acompanhamento muito de perto, até porque envolve muitas vezes a própria sobrevivência da indústria ou a manutenção de sua vantagem competitiva. Klintoe define "informação para indústria como o esforço intelectual para estimular os administradores e técnicos de uma empresa, pública e privada, no sentido de aperfeiçoar suas operações e inovar métodos, processos produtivos e serviços, mediante a conversão em resultados práticos de toda a forma de conhecimento obtido por qualquer meio"16. O mesmo autor diferencia, em termos conceituais, "informação para a indústria" de "informação industrial" e conceitua informação industrial como "o esforço de coletar, avaliar e tornar disponível informações sobre o setor industrial e suas operações produtivas, gerando dados técnico-econômicos, informações sobre tecnologias utilizadas, estrutura industrial, produtividade setorial, estudos de viabilidade, dados de investimentos e retorno, implantação de indústrias, transferência de tecnologia, dentre outros"16. É portanto, todo o conhecimento que permite comparar condições nacionais, oportunidades, operações internacionais e assim fornecer orientação aos investimentos públicos e privados, subsidiando formulação de políticas e tomadas de decisão. Porter considera que a informação representa importante papel no processo de inovação, o qual muitas vezes resulta em investimentos simples em P\&D. Freqüentemente, resulta no esforço de olhar no lugar certo, não obstruído por suposições cegas ou pelo conhecimento convencional ${ }^{17}$.

É importante dizer que não há claramente um divisor de águas nos vários conceitos que determinam a informação científica e tecnológica. Elas se complementam, estão associadas no momento do seu uso e de sua aplicação. A informação científica é aberta, pela própria natureza do trabalho científico. A informação tecnológica tem um mercado, por isso mesmo é reservada, muitas vezes tem caráter de sigilo. A informação para a indústria é o estímulo para o avanço tecnológico e também um recurso estratégico, é uma commodity, um bem, porque tem valor de mercado, sobretudo na área tecnológica e industrial. Para que a informação seja um recurso estratégico com valor de mercado, precisa ser utilizada com rapidez e segurança.

O volume de dados hoje existente e o crescimento exponencial da informação são exigências para a sua organização em sistemas de informação automatizada voltados para atender às necessidades de seus usuários. Hoje, além dos bancos de dados, são as novas tecnologias de informação que permitem trabaIhar com rapidez grandes volumes de dados, com respostas precisas capazes de antecipar mudanças e trazer vantagens competitivas. Estas ferramentas são de fundamental importância para a inteligência competitiva.

A recuperação da informação é determinante para a informação automatizada. É de importância capital que seja planejada com cuidado, sobretudo no que diz respeito ao sistema de indexadores a ser utilizado como chave de recuperação, porque por meio deles serão definidas as consultas e relatórios de saída. O processo de indexa- 
ção objetiva estruturação e consolidação do sistema de informação, facilitando não só o registro e recuperação das informações, mas também a organização das séries históricas. São ferramentas que precisam ser previamente definidas, de forma a serem direcionadas para atender às demandas dos usuários e, ao mesmo tempo, agregar valor à informação. Indexação é a representação do conteúdo temático dos documentos, utilizando termos de estruturas hierárquicas, como tabelas, classificações, vocabulários controlados, listas de termos significativos e até mesmo a própria linguagem natural, de forma a possibilitar o armazenamento, as estratégias de busca, recuperação e pesquisa das informações, tendo como ponto de acesso os termos que Ihes foram atribuídos ${ }^{18}$.

É interessante lembrar que a Inteligência Competitiva faz uso de todos os tipos de informação e de suas fontes diversas. Salientamos ainda que, além do conhecimento científico e tecnológico, existem informações em forma de indicadores que retratam o movimento de setor de C\&T e que são de extrema importância para o acompanhamento do desenvolvimento de um país e das quais a Inteligência Competitiva também faz uso. O Banco Interamericano de Desenvolvimento, (BID) define indicador como uma "especificação quantitativa e qualitativa para medir o atingimento de um objetivo. Também é definido como a expressão numérica de um objetivo"19. Neste contexto, a informação está sempre ligada aos conceitos de relevância e pertinência. De acordo com Saracevic, relevância é o contato efetivo entre fonte e destinatário e pertinência é a resposta adequada ao que foi demandado ${ }^{20}$. Finalmente, esta evolução de conceitos permite introduzir uma classe de informações geradas através de um dos ciclos brasileiros de financiamento em C\&T, ou seja, as informações de projetos financiados pela Finep, definidas como um conjunto de dados, especificações técnicas e financeiras de produtos, processos e serviços, geradas pelos seus clientes e que retratam o movimento brasileiro rumo ao desenvolvimento científico e tecnológico, no contexto deste estudo.

\section{A INTELIGÊNCIA COMPETITIVA}

O conceito de inteligência competitiva surgiu na década de 80, como uma disciplina capaz de integrar o planejamento estratégico, atividade de marketing e de informação, objetivando o monitoramento constante do ambiente externo, com respostas rápidas e precisas à empresa no que diz respeito aos movimentos do mercado. O que torna o processo de inteligência competitiva diferente é a geração de resultados em horas ou dias, em vez de semanas e meses, normalmente requeridos com as metodologias tradicionais de pesquisa e planejamento, além da ênfase em perspectivas estratégicas em vez de exatidão numérica. $O$ tempo para a inteligência competitiva é fator fundamental para que seu uso possa antecipar. Caso contrário, a informação deixa de ter um valor de agregação, de inovação, de progresso, de estratégia. Na verdade, o valor da informação está diretamente relacionado à otimização do seu uso, e este é determinado por uma demanda e pela velocidade com que se aplica o resultado do levantamento dos mais variados tipos de informação.

Neste contexto, a inteligência competitiva é sinônimo de capacidade de antecipar as ameaças e novas oportunidades por meio da informação validada para a tomada de decisão, em um processo contínuo em que a informação é transformada em conhecimento no processo decisório da empresa, cujo resultado final é na verdade "informação com valor agregado". Um sistema genérico de inteligência competitiva deve ser capaz de contemplar as dimensões tecnológica, econômica, política e social. Funciona como uma antena na identificação de novas oportunidades e sinais de mudança do ambiente. Ao mesmo tempo, ajuda a empresa a não perder o foco estratégico no processo de coleta, armazenamento e análise da informação. Necessita portanto, da estrutura de um programa sistemático de coleta e análise de informação em fontes diversas, formais e informais e em redes de especialistas. A Inteligência Competitiva trata da informação estratégica para a tomada de decisão, cuja coleta passa por várias fontes e tipos de informação e a análise é elaborada por diferentes especialistas. Envolve dados econômi- co-financeiros, de mercado, cenários, clientes, fornecedores, transformados em "informação com valor agregado" para a tomada de decisão e, ao mesmo tempo, monitora as metas estratégicas da empresa ${ }^{21}$.

A informação organizada, sistematizada e automatizada tem papel relevante nos dias de hoje, no mundo em que a hiperinformação é uma realidade, especialmente quando pensamos na Internet, a maior rede mundial de computadores, que diminui distâncias, derruba fronteiras, com grande capacidade de integração e é o próprio símbolo de associação de velocidade, tecnologia e informação. No entanto, é necessário saber usá-la, não só no sentido de nos mantermos atualizados, mas sobretudo porque se manter informado e saber usar bem a informação é uma vantagem competitiva, a inteligência competitiva consolida esta afirmação.

A organização da informação em sistemas e redes, tendo como ferramentas de suportes equipamentos de alta velocidade, com grande capacidade de armazenamento e recuperação, provocou mudança de paradigma e nos levou ao mundo encantado da informação, onde praticamente o apertar de um botão muda a compreensão das coisas e nos leva a um mundo sem fronteiras, mas altamente competitivo. Capra afirma que "pensar sistemicamente" inverteu o paradigma científico: onde se supunha que o todo era compreendido a partir de suas partes, hoje o entendimento é a partir da dinâmica do todo. Ao mesmo tempo, o pensar sistêmico provoca a mudança do pensar em termos de "estrutura" para se pensar em termos de "processo", onde a estrutura é uma manifestação do processo ${ }^{22}$. O pensamento sistêmico permite a relação de redes que representam os fenômenos em observação. Hoje, as organizações são vistas como um todo orgânico, e esta nova forma de olhar é oriunda do trabalho de Bertalanffy $^{23}$. Organizar a informação em sistemas e em redes permite que a informação flua velozmente e, portanto, é de importância capital para a sociedade da informação, para a empresa moderna e para a própria Inteligência Competitiva.

A Inteligência Competitiva está fundamentada na informação, na informação 
formal e informal, na informação estruturada em sistema de informação e pode ser definida como "um processo formal por meio do qual as informações são coletadas, processadas e disseminadas dentro da empresa nos níveis estratégico e tático, visando à definição e à execução de suas estratégias, bem como a avaliação de sua efetividade ${ }^{21}$. Portanto, o Sistema de Inteligência Competitiva foca as metas estratégicas e o posicionamento no mercado, sua matéria-prima é a informação, advinda de uma demanda, de uma necessidade da empresa em se manter competitiva e dominar o seu mercado. Tem como característica principal o rastreamento e a identificação de ameaças e novas oportunidades para manutenção de posição no mercado. A figura 1 mostra as principais características de um Sistema de Inteligência Competitiva, as quais se fundamentam nas necessidades de informação estratégica, no grau de adequação das fontes de informação a essas necessidades, na disponibilidade de recursos financeiros, humanos e de informática na empresa.

\section{O Sistema de Inteligência Competitiva}

A aceleração das mudanças tecnológicas, a globalização, atomização dos mercados, desregulamentação dos mercados e a explosão informacional alavancada pelas novas tecnologias de informação são fatores que exigem das empresas, para que se mantenham competitivas na chamada aldeia global, o estabelecimento de mecanismos de monitoramento em tempo real, que permitam antecipar mudanças no ambiente externo e identificar ameaças e oportunidades. A Inteligência Competitiva pode oferecer uma organização e infra-estrutura para que seja possível este monitoramento.

O Sistema de inteligência competitiva é o processo organizacional de coleta e análise sistemática da informação, disseminada como inteligência aos usuários, em apoio à decisão, nos níveis estratégico e tático. Inteligência é o resultado que começa com a coleta de dados. Esses dados são organizados e transformados em informação, que, depois de analisada e contextualizada, transforma-se em inteligência. Esta, por

FIGURA 1

\section{Sistema de Inteligência Competitiva}

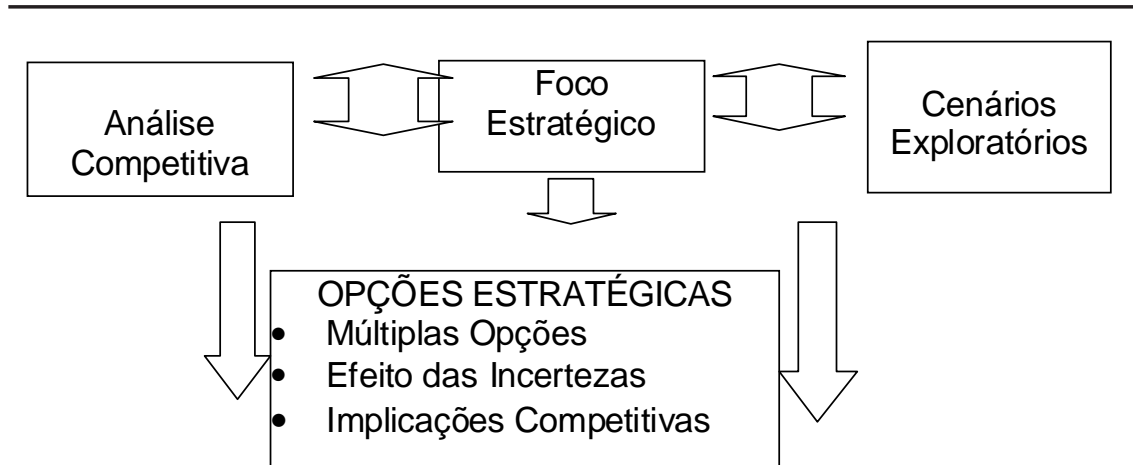

Schoemaker et al., 1992 Stollenwerk, 1997

FIGURA 2

Vantagens e necessidades

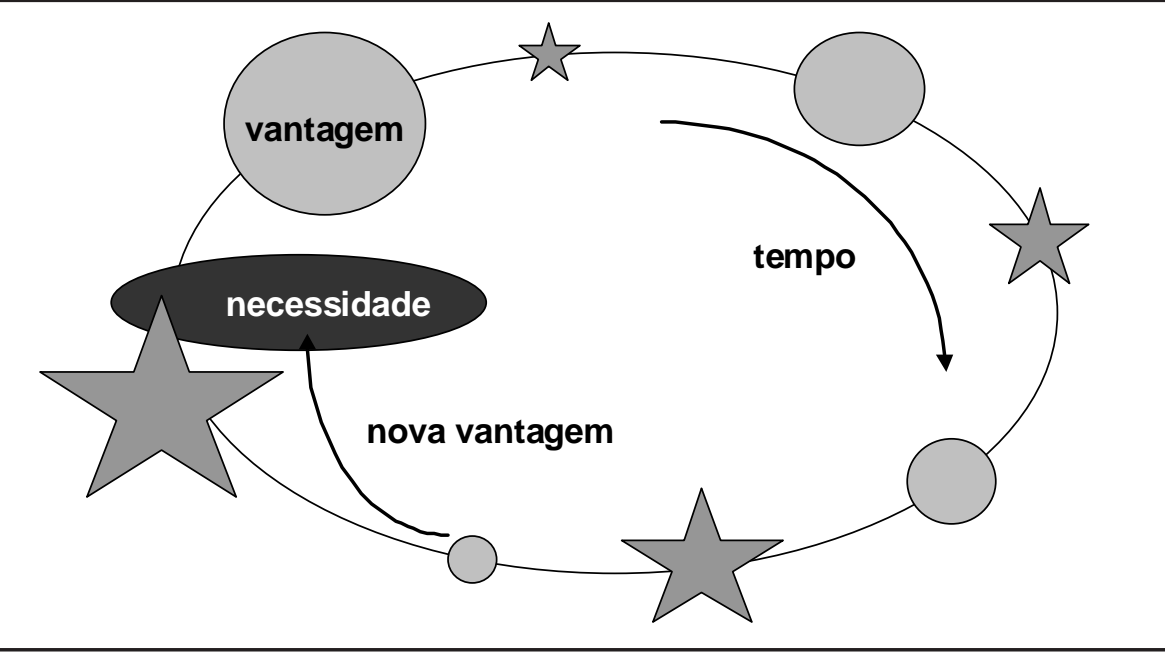

Fonte: DOU, 1997

sua vez, aplicada aos processos decisórios gera vantagem competitiva para a organização. Trata-se, portanto, de um processo contínuo em que a informação é transformada em conhecimento no processo decisório da empresa. Os sistemas de Inteligência Competitiva são exclusivos de cada empresa, pois seus projetos baseiam-se fundamentalmente nas necessidades de informação estratégica e nas necessidades de recursos existentes.

Para as empresas de um modo geral, as vantagens e necessidades nesse processo são cíclicas, à medida que nova necessidade gera uma vantagem que trará nova necessidade e assim por diante. Uma vantagem competitiva não é, jamais, uma aquisição estática, um bem permanente. Ela é sujeita a mudanças e tende a diminuir com o tempo, enquanto novas necessidades vão sendo sinalizadas pelo mercado.

Portanto, as principais funções da inteligência competitiva são justamente a identificação das oportunidades ainda emergentes que geram necessidades, bem como a capacitação da empresa no sentido de obter novas vantagens competitivas para atender às necessidades advindas das novas oportunidades. A figura 2 explicita bem este ciclo. 
O Sistema de Inteligência Competitiva possibilita monitorar tanto o ambiente externo, quanto o interno. Ao monitorar o ambiente externo no que diz respeito à concorrência, analisa o poder de barganha dos concorrentes, fornecedores, o poder de negociação dos clientes, ameaças de novos entrantes e de novos produtos e serviços substitutos. Reconhece também fatores macroambientais, tais como políticos, econômicos, sociais que influenciam diretamente a atuação da empresa e todo segmento industrial e de serviços. Quanto ao ambiente interno, acompanha o desenvolvimento das competências essenciais, disponibilização dos recursos financeiros e humanos e ajustes de suas estratégias diante das exigências do ambiente externo. A utilização de tais sistemas permite acompanhar, de forma contínua, os processos de revisão das estratégias de negócio, de inovação tecnológica e oferece suporte à tomada de decisão em nível estratégico, tático e operacional. Tayson afirma que a chave para o sucesso de um sistema de inteligência na organização é sua total integração com o processo de planejamento estratégico. O Sistema de Inteligência Competitiva, para cumprimento de suas funções, precisa ter uma abordagem estruturada e estratégica compreendendo as seguintes etapas representadas pela figura 3 .

$\Rightarrow$ planejamento e coordenação;

$\Rightarrow$ coleta, processamento e armazenamento da informação;

$\Rightarrow$ análise e validação da informação;

$\Rightarrow$ disseminação e utilização da informação estratégica;

$\Rightarrow$ avaliação do processo.

\section{Planejamento e Coordenação}

FIGURA 3

\section{Processo de Inteligência Competitiva}

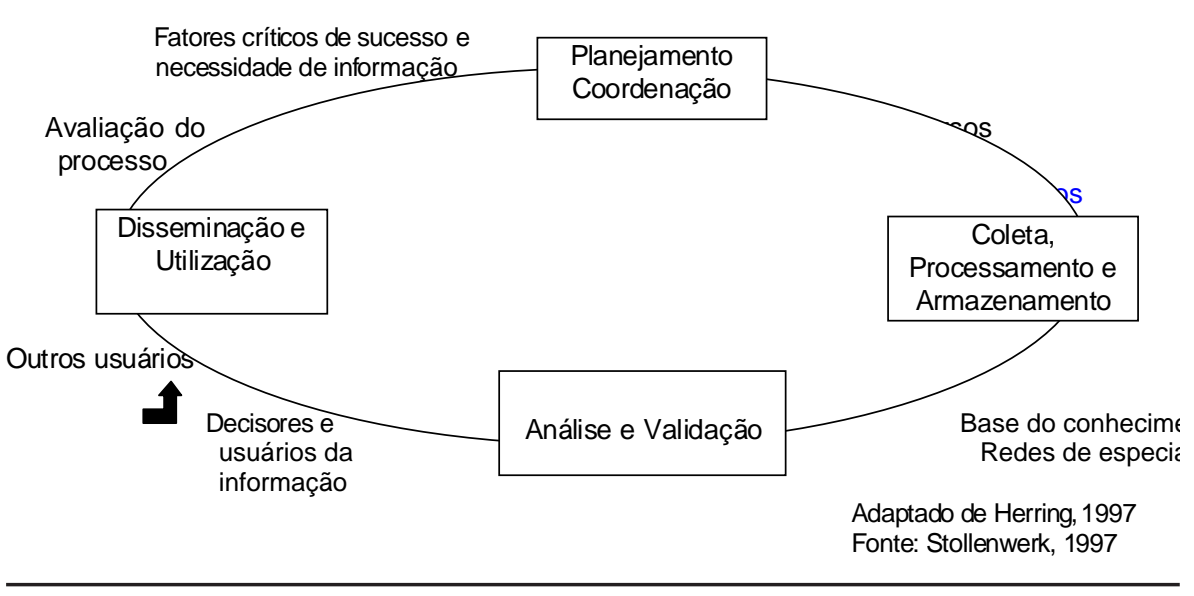

É a etapa mais importante do processo de Inteligência Competitiva, porque é na atividade de planejamento e coordenação que as necessidades de informação estratégicas são levantadas para estruturar o próprio Sistema de Inteligência Competitiva e sobretudo quem vai usá-la, quais os usuários/ clientes. Nesta fase, são identificadas as necessidades de informação para suportar o processo decisório direcionadas para os negócios da empresa, utilizando-se geralmente o método dos Fatores Críticos de Sucesso (FCS). Fatores Críticos de Sucesso são definidos por Rockart como "elementos de postura estratégica essenciais para assegurar ou melhorar a posição competitiva da empresa frente à concorrência"24. Fatores Críticos de Sucesso são, para qualquer empresa, o número limitado de áreas nas quais os resultados, se forem satisfatórios, irão assegurar um desempenho competitivo de sucesso para a organização. Não devem ser confundidos com os objetivos ou com as estratégias da empresa. Os objetivos definem o que a empresa deseja alcançar e as estratégias definem como alcançar os objetivos. Os Fatores Críticos de Sucesso são os meios que garantem a realização dos objetivos, permitindo, ao mesmo tempo, uma posição mais objetiva referente à estratégia de implantação do Sistema de Inteligência Competitiva. A característica principal dos Fatores Críticos de Sucesso (FCS) é de arborescência, por esta razão se recomenda que sejam definidos poucos fatores críticos, não mais de uma dezena, porque serão desdobrados, por meio de objetivos e metas, até o nível dos processos-chave ou das necessidades de cada gerente ou especialista ${ }^{21}$. O desdobramento dos fatores críticos em árvores hierárquicas de pertinência permite reconhecer a importância relativa de cada ramificação da árvore e identificar meIhor as linhas de difusão da informação aos usuários. Constitui, portanto, importante ferramenta de análise, sendo geralmente elaborada por grupos de especialistas das áreas envolvidas ${ }^{24}$.

\section{Coleta, Processamento e Armazenamento da Informação}

Constitui o centro nervoso do sistema, e normalmente as organizações exercitam esta atividade para administração dos seus negócios, muitas vezes de forma não sistemática. A coleta, processamento e armazenamento da informação dentro da estrutura de um Sistema de Inteligência Competitiva precisa ser consolidada e aperfeiçoada de forma sistemática, acompanhando as metas estratégicas e a cada mudança de foco estratégico. Faz toda a cobertura das necessidades de informação, incluindo as operacionais e até mesmo as individuais.

Na fase de coleta, estrutura-se a informação que será analisada para produzir inteligência. São encontradas nas informações publicadas ou não e estão disponíveis nas fontes internas e externas. É importante lembrar que toda informação que trate do setor/ segmento industrial e tecnologias associadas/correlacionadas às atividades de uma empresa constitui-se em 
informações que devem ser coletadas, tratadas e analisadas sistematicamente, ou seja, aquela informação que esteja relacionada com os Fatores Críticos de Sucesso (FCS) da empresa. Esta pode ser coletada em fontes formais - passado recente, são informações geralmente publicadas e são de domínio público, facilmente encontradas nas bases de dados, revistas especializadas, teses, patentes. As fontes informais de informação, geralmente informações não publicadas, geralmente são externas e envolvem o futuro próximo e o presente. Agregam valor à inteligência e podem ser obtidas por meio de contatos pessoais ou telefônicos com clientes, fornecedores, concorrentes e consultores em congressos, exposições, reuniões, jantares, entrevistas, ou levantamentos em listas telefônicas, folders etc. O monitoramento tecnológico pode ser realizado com ampla abrangência, graças à análise de quatro grandes tipos de informação que devem ser levadas em conta, neste processo. Trata-se da informação científica, técnica, tecnológica e técnico-econômica. Os dois primeiros tipos são bem cobertos por bases de dados (teses, artigos de periódicos, apresentações em congressos, patentes), porém os dois últimos tipos ainda não contam com uma estrutura de bases de dados: a tecnológica refere-se à informação industrial, e a técnico-econômica refere-se à informação mercadológica (clientes, fornecedores, concorrentes, comércio etc.)

Fuld, em seu livro The New Competitor Intelligence, afirma que existem dois tipos de informação: primária e secundária. A primária é apresentada como uma fonte original de informação; e a secundária, como uma fonte que registra ou interpreta a informação primária. Fuld alerta para o fato de que a informação primária é a mais difícil de ser conseguida, porém é a que tem maior validade e qualidade ${ }^{27}$. Jakobiak, em seu livro Que sais - je? Information scientifique et tecnique, escreve que, para uma melhor compreensão, é necessário classificar a informação em diferentes tipos, formas, classes e suportes, e apresenta a seguinte tipologia de informação, representada pela figura 4, onde expressa, de forma resumida, as diferenças não

FIGURA 4

Tipologia de informação por Jakobiak

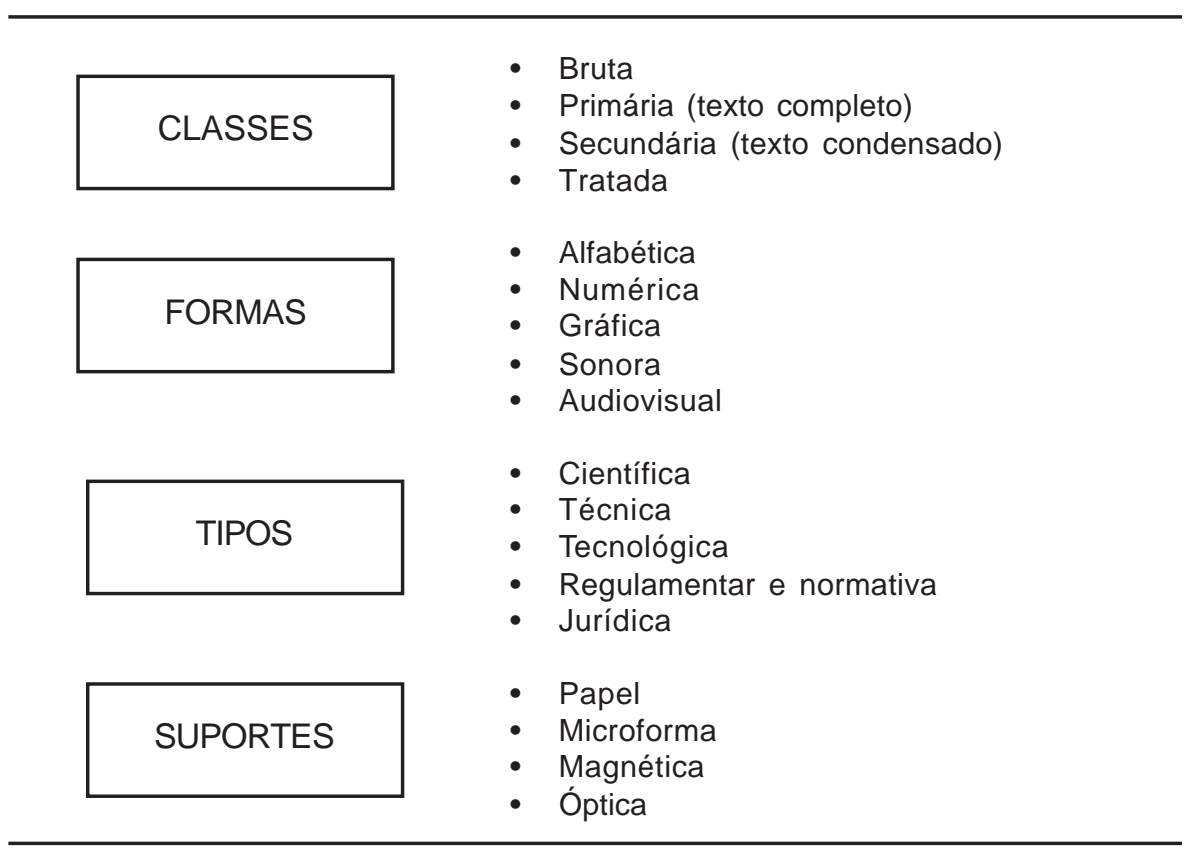

Fonte: Jakobiak, 1995

FIGURA 5

Cadeia básica complementar de informação

\section{CADEIA BÁSICA}
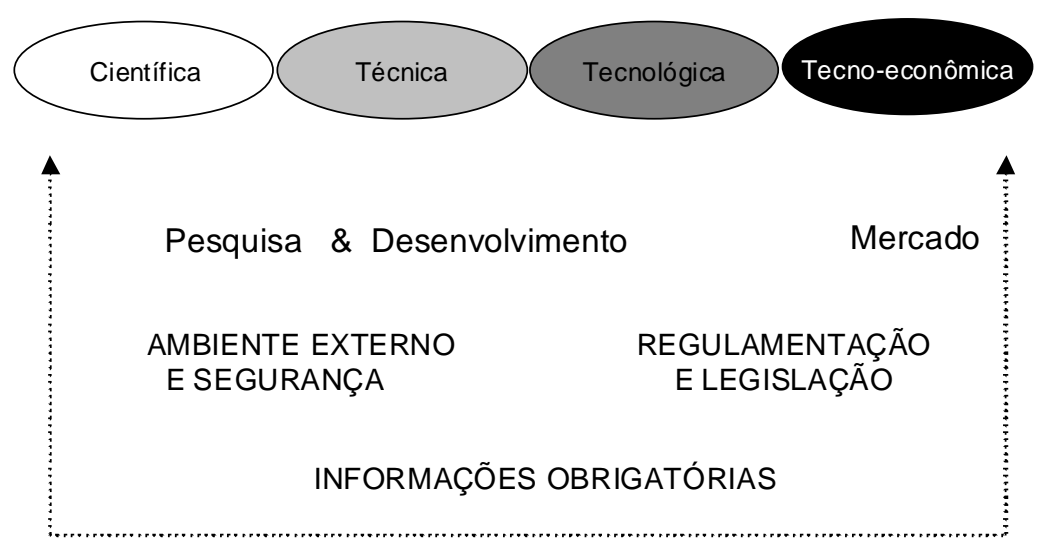

(CADEIA COMPLEMENTAR)

Fonte: Jakobiaki

só nos tipos de informação, como também nos meios pelos quais é divulgada e disseminada ${ }^{28}$.

Ainda, o mesmo autor, ao definir os diferentes tipos de informação, apresenta uma cadeia básica, que caracteriza a evolução da informação que vai desde a geração da idéia, pesquisa e desenvolvimento até a sua comercialização pelo mercado. A figura 5 mostra a cadeia básica e complementar de informação de Jakobiak, onde os vári- os tipos de informação se complementam para responder às demandas de um sistema de inteligência competitiva e o nível de complexidade que apresentam. 
Ao mesmo tempo define cada tipo de informação e onde pode ser usada. A informação científica circula principalmente no meio acadêmico, e é necessária à fase de laboratório da pesquisa básica, aplicada ou do desenvolvimento experimental. Ela corresponde à informação formal e está contida nas revistas científicas, teses, relatórios internos, anais de congressos, e geralmente está disponível nas bases de dados. A informação técnica é necessária na fase que antecede a concretização de decisões. Trata-se do "estado-da-arte" e caracteriza-se sobretudo pelas informações contidas nas patentes. Também este tipo é coberto pelas bases de dados internacionais como STN, Dialog, Quest-Orbit, Data-Star, inclusive com acesso pela Internet, e mais recentemente em cd-rom. A informação tecnológica é a informação que retrata a realização prática do desenvolvimento, o que significa colocar em operação as unidades industriais, mediante construção de protótipos, de unidades piloto. Complementa as informações contidas nas patentes, caracterizando o "saber fazer" o know how (15). A informação técnico-econômica está situada na fronteira entre os dois tipos: tecnológica e econômica. Refere-se aos dados macroeconômicos apontados pelos países em forma de resultados, estratégias, cooperação, parcerias, produtos, unidades de produção e os mercados. Estes dois últimos tipos de informação são cobertos precariamente pelas bases de dados, entretanto existem alguns poucos no mercado. Há, ainda, a considerar as informações do tipo complementar que dizem respeito aos aspectos regulamentares e normativos, jurídicos, de segurança e meio ambiente, os quais devem ser considerados na fase de concepção do projeto de pesquisa. Observamos que, tanto os autores americanos quanto os franceses, seguem a mesma linha de abordagem quando a questão está relacionada com a tipologia da informação. Stollenwerk apresenta, em sua dissertação do DEA, uma tabela de tipologia de informação proposta pelo CRRM que resume o explicitado acima e, ao mesmo tempo, mostra a complexidade de cruzamento exigido pelo Sistema de Inteligência Competitivo²1. Ver figura 6.
FIGURA 6

Tipologia e complexidade da informação

\begin{tabular}{|c|c|c|c|}
\hline $\begin{array}{l}\text { TIPOLOGIA } \\
\text { DA INFORMAÇÃO }\end{array}$ & CONTEXTO & FONTES & MEIOS DE SUPORTE \\
\hline & Científico & $\begin{array}{l}\text { Publicações } \\
\text { científicas }\end{array}$ & \\
\hline $\begin{array}{l}\text { Texto } \\
(40 \%)\end{array}$ & $\begin{array}{l}\text { Tecnológico } \\
\text { Técnico- } \\
\text { econômico } \\
\text { Econômico } \\
\text { Mercadológico } \\
\text { Meio ambiente } \\
\text { Segurança } \\
\text { Jurídico } \\
\text { Regulamentar }\end{array}$ & $\begin{array}{l}\text { Seminários } \\
\text { Patentes } \\
\text { Literatura técnica } \\
\text { geral } \\
\text { Relatórios anuais } \\
\text { e Publicações das } \\
\text { Empresas } \\
\text { Normas } \\
\text { Teses } \\
\text { Relatórios } \\
\text { externos }\end{array}$ & $\begin{array}{l}\text { Papel } \\
\text { Magnéticos: base de } \\
\text { dados on-line } \\
\text { Plástico: Microfilmes e } \\
\text { microfichas } \\
\text { Laser: CD-ROM e } \\
\text { CD-Audio } \\
\text { Internet }\end{array}$ \\
\hline $\begin{array}{l}\text { Especialistas } \\
(10 \%) \\
\text { Informal }\end{array}$ & & $\begin{array}{l}\text { Memória técnica } \\
\text { da empresa e } \\
\text { informação } \\
\text { interna }\end{array}$ & $\begin{array}{l}\text { Base de dados } \\
\text { interna } \\
\text { Intranet, Papel }\end{array}$ \\
\hline $\begin{array}{l}(40 \%) \\
\text { Feiras e } \\
\text { Congressos }\end{array}$ & & $\begin{array}{l}\text { Redes de } \\
\text { pessoas de } \\
\text { origens diversas }\end{array}$ & $\begin{array}{l}\text { Oral } \\
\text { Internet }\end{array}$ \\
\hline$(10 \%)$ & & $\begin{array}{l}\text { Prospectos, } \\
\text { publicidade, } \\
\text { contatos informais }\end{array}$ & Texto, Oral, Internet \\
\hline
\end{tabular}

Fonte: CRRM, Stollerrwerk, 1997

Dentro desse contexto, é oportuno ressaltar que a seleção das fontes de informação na montagem de um sistema de inteligência competitiva torna-se fundamental para sua eficiência e eficácia.

\section{Análise e validação da informação}

A informação coletada, processada e armazenada na etapa anterior necessita ser analisada e validada pelos especialistas da área. É recomendável que a validação seja feita por meio do consenso. Essa atividade pode ser realizada por redes de especialistas, de forma iterativa e em reunião específica para cumprimento desse tipo de tarefa. A análise e validação da informação é o sustentáculo de um Sistema de Inteligência Competitiva, é necessário que ocorra na velocidade, urgência e prioridade que se fizerem necessárias para a tomada de decisão, e sobretudo deve ser oportuna.

\section{Disseminação e utilização da informação estratégica}

O ciclo do processo da Inteligência Competitiva encerra-se com a disseminação e utilização da informação estratégica para a tomada de decisão. Tal informação passou pelas etapas de coleta, processamento, armazenamento, análise, validação e representa uma síntese destas etapas. O seu uso pelos tomadores de decisão é de extrema importância, porque só assim é possível avaliar o seu real valor, especialmente porque este valor representa um conhecimento, que por sua vez, ao ser usado de forma correta, vai gerar sucesso e com certeza acrescentará vantagem competitiva e posicionamento de mercado não só em termos de expansão, como e principalmente na penetração em novos nichos de mercado. O objetivo maior da Inteligência Competitiva é fazer chegar a infor- 
mação analisada, validada e que custou caro, à pessoa certa, em tempo hábil e no formato adequado para a tomada de decisão. A apresentação da informação exige cuidados. Para a alta administração, o tipo de relatório deve ser o mais resumido possível, mostrando os impactos possíveis na avaliação do posicionamento da empresa com foco em suas estratégias competitivas. Em nível gerencial a análise é mais minuciosa porque é necessário maior detalhamento técnico e informações sobre os concorrentes. Stollenwerk recomenda que este tipo de relatório seja elaborado com a ajuda da bibliometria, tendo como principal fonte bases de dados de patentes ou de literatura ${ }^{21}$.

\section{INTEGRAÇÃO DOS ELEMENTOS DA INTELIGÊNCIA COMPETITIVA PARA CONSTRUÇÃO DO SISTEMA DE INFORMAÇÕES DE CLIENTES PARA FINEP}

Os fundamentos e sobretudo os componentes da Inteligência Competitiva servem de base para a construção do modelo de sistema de informação de clientes da Finep. Para uma organização, o sistema de informação deve estar a serviço de seus objetivos e funções, subsidiando o processo global e os vários níveis de ação, de acordo com a dinamicidade que caracteriza a administração de uma empresa. Nesse sentido, o sistema de informação se insere no processo dinâmico e contínuo de decisão e ação, oferecendo informação diferenciada para cada nível de decisão a ser tomada. Para a Finep, o domínio em termos do conhecimento de seus clientes é uma necessidade premente, porque vai ajudála a desempenhar com sucesso os seus negócios. As organizações modernas são fundamentadas na informação e no conhecimento, e cada vez mais a gestão é feita por especialistas com a eliminação crescente dos níveis hierárquicos. É adaptação aos novos tempos. Segundo Toffler, a disseminação desta nova forma de gestão é decorrente da economia globalizante, responsável pelo crescimento da concorrência internacional, fazendo com que as organizações bem-sucedidas trabaIhem a informação e o conhecimento como um capital de valor estratégico ${ }^{29}$. A Inteligência Competitiva tem os seus elementos sustentados pela informa-

FIGURA 7

Elementos da Inteligência Competitiva

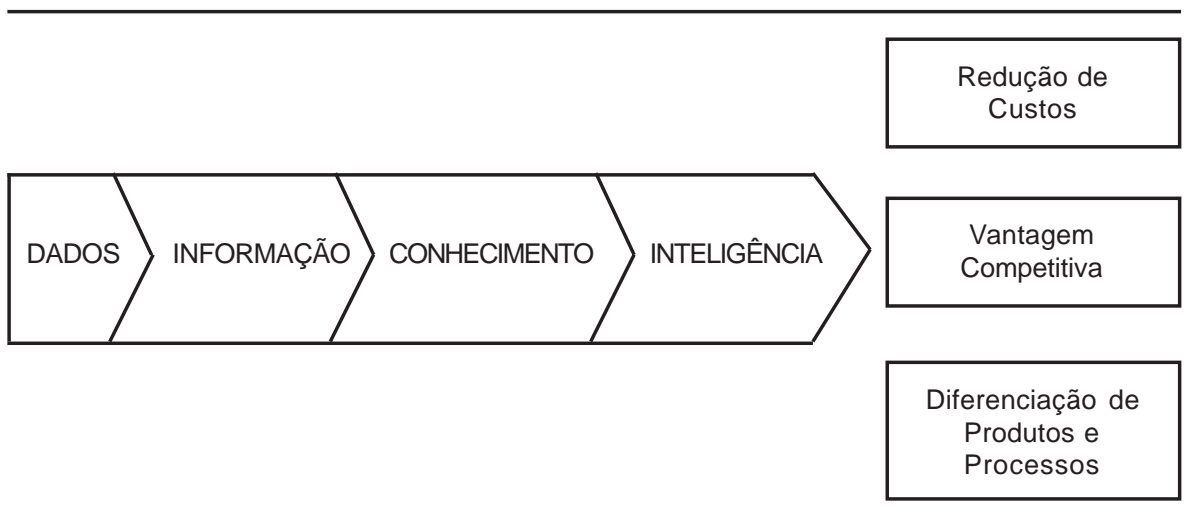

Fonte: Stollenwerker - Petrobrás, 1997

ção e o conhecimento com o objetivo maior de ajudar as organizações a terem uma postura empreendedora, adotando uma estratégia sempre inovadora. A Finep está buscando este caminho, é o seu grande desafio administrativo para os próximos anos. Os elementos da Inteligência Competitiva serão os pilares de sustentação para a construção do modelo de Sistema de Informação de Clientes para a Finep como uma necessidade de integração com o seu novo modelo de gestão advindo do Processo de Transformação. São eles: o Dado, enquanto material de coleta, a informação, enquanto dado tratado, o conhecimento, enquanto 'acervo' do Cliente - Finep, e, por fim, a Inteligência, enquanto informação analisada e validada para sustentação de vantagens competitivas. Definidos operacionalmente, seus conceitos podem ser assim descritos:

- DADOS - É a coleta de matéria-prima bruta, dispersa nos documentos.

- INFORMAÇÃO - É o tratamento do dado, transformado em Informação. Pressupõe uma estrutura de dados organizada e formal. As bases e bancos de dados, bem como as redes são sustentadas pela informação.

- CONHECIMENTO - É o conteúdo informacional contido nos documentos, nas várias fontes de informação e na bagagem pessoal de cada indivíduo.

- INTELIGÊNCIA - É combinação destes três elementos resultante do processo de análise e validação pelo especialista. É a informação com valor agregado.

A relação entre os elementos da Inteligência Competitiva a serviço da gestão estratégica, está graficamente expressa na figura 7 .

Metodologicamente, a relação 'dadosinformação-conhecimento-inteligência' para a gestão estratégica da Finep se traduz na proposta de construção de Sistema de Informação de Clientes, cujos elementos são apresentados a seguir.

\section{Fontes internas}

As fontes internas são informações geradas pela própria Finep, sobretudo aquelas que dizem respeito aos clientes por meio de propostas de financiamento (projetos) por ela selecionados, analisados, monitorados e avaliados. Informações geradas pelo corpo técnico da Finep; estudos setoriais; análise técnica das operações de financiamento; parecer técnico; informações de crédito e financeiras; informações comprobatórias; indicadores de progresso, trabalhos técnicos elaborados pelo corpo funcional, relatórios técnicos dos projetos financiados etc.

\section{Fontes Externas - Clientes}

As fontes externas serão os próprios clientes. Para efeito da construção 
deste arcabouço, estamos considerando "Cliente Finep" todas as instituições e empresas que receberam/recebem ou são candidatas ao seu apoio financeiro ou estejam ligadas a ela mediante alguma parceria ou algum trabalho conjunto. Os clientes Finep se inserem no macroambiente, isto é governo, empresas, universidades e a sociedade, universo com o qual a Finep se relaciona. Portanto, as informações serão capturadas por meio dos dados sobre os clientes para explicitar o posicionamento no mercado e capacidade de competitividade. Tais informações cobrem todo o expectro da empresa/instituição, a saber:

- informações cadastrais sobre composição social e do capital da empresa;

- informações necessárias à análise de crédito, de cadastro, econômico-financeira e garantias;

- informações necessárias para a contratação: análise de crédito, análise técnica, Decisão de Diretoria - Finep e informações comprobatórias (certidões negativas);

- informações sobre linha de produtos e serviços e sua relação com o processo de inovação e transferência de tecnologia, informações relativas ao Inpi (patentes requeridas, concedidas, contratos de transferência de tecnologia);

- informações sobre atividades e infraestrutura de P\&D.

Por último, deverão atender às necessidades de planejamento e operacionais da Finep no que diz respeito a análise de projetos; fomento; diagnósticos setoriais; séries estatísticas; construção de cenários.

\section{Estrutura de Dados}

A Estrutura de Dados é o resultado de pesquisa nos documentos referentes

\section{FIGURA 8}

\section{Estrutura de Informação do Sistema}

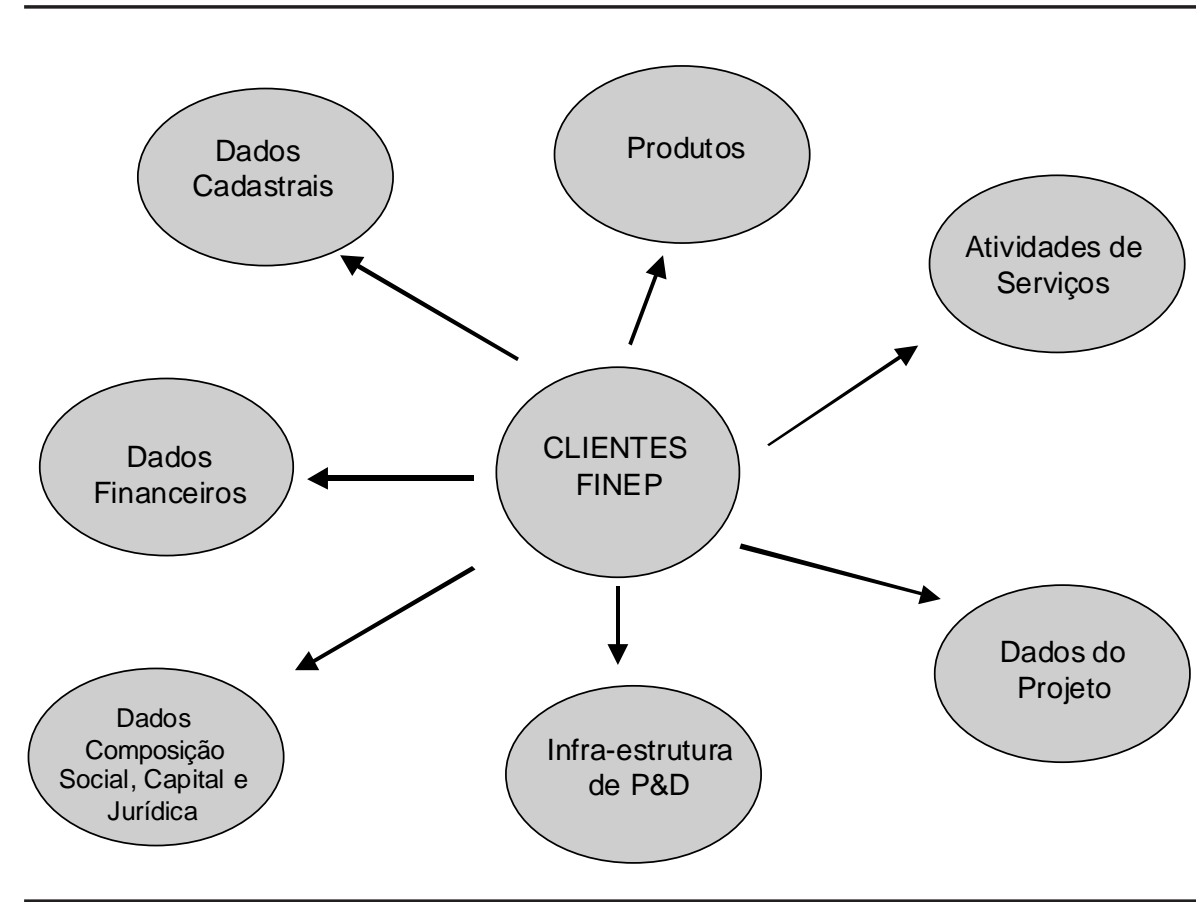

aos clientes, nos roteiros de financiamento, no Sistema de Informação Corporativa, nos formulários de apresentação de solicitação de financiamento e nos documentos da Finep. A figura 8 mostra a Estrutura de Dados que comporá o Sistema de Informações de Clientes da Finep*.

O universo das empresas e instituições será aquele que compõe a atual carteira de projetos da Finep, perfazendo um total de 1.500 registros. Serão classificadas de acordo com o Sistema de Indexadores da Finep, excetuando-se a classificação de porte, que será a estabelecida pelo Sebrae. A coleta de dados será realizada por meio de formulário eletrônico e em papel, acompanhado de seus anexos: tabelas e instruções para preenchimento. Devese esclarecer a conveniência da escolha do meio para o fornecimento dos dados, consultando o órgão sobre a forma escolhida: formulário, disquete ou

"Para melhor entendimento e especificidade dos dados ver:

BATTAGLIA, Maria da Glória Botêlho. A Inteligência Competitiva como suporte para a construção de um modelo de Sistema de Informação de Clientes para a Finep. Rio de Janeiro / Marseille, CEIC / DEA. Mémoire en vue de l'obtention du Diplome d'Etudes Approfondies DEA.,1998. via Internet. Na verdade, é uma consulta que exige a divulgação prévia.

O instrumento de coleta de dados deve ser encaminhado aos diretores das instituições, solicitando resposta com brevidade. Caso a devolução não tenha sido efetuada, mensagem de cobrança deverá ser transmitida via correio. Um sistema em microcomputador deve ser montado para o monitoramento da fase de coleta. Os dados serão globalmente atualizados a cada dois anos. O Sistema de Informações de Clientes da Finep deverá estar disponível em rede interna para toda a Finep e via Internet só com as informações consideradas não sigilosas. 0 software será compatível com o sistema de informação corporativa, permitindo a recuperação de informação a partir das chaves de busca especificadas a seguir. Deve permitir também recuperação mediante busca booleana. As principais chaves de recuperação serão planejadas de acordo com as necessidades internas e externas da Finep. É bom lembrar que, quando falamos de recuperação, já estamos falando de Informação, sobretudo de informação com valor agregado porque Ihe foram atribuídas classificações e indexadores. A recuperação não trabaIha com o dado, e sim com a informação, que já foi classificada, indexada, 
e, portanto, oferece garantia de padronização e consistência. Quanto mais precisa for a recuperação, mais valor agregado terá a informação. As chaves de recuperação vão definir os relatórios de saída atendendo às necessidades de informação estratégica, operacionais e de algumas demandas externas. Visualizam-se alguns resultados como produtos das chaves de recuperação, a saber:

1. As áreas de resultados poderão ter insumos para construção de cenários, diagnósticos setoriais, formulação de políticas, identificação de novas oportunidades de financiamento;

2. criação de novos produtos, séries históricas e indicadores;

3. as áreas operacionais serão beneficiadas nas atividades de análise, acompanhamento, avaliação de projetos, fomento, séries históricas e indicadores;

4. a área de marketing se beneficiará para monitorar a satisfação do cliente, a identificação dos clientes potenciais, e para trabalhar as estratégicas de marketing;

5. atendimento das demandas externas de informação, no sentido de disponibilizar, no formato de referência bibliográfica ou outro formato qualquer, as informações que não tenham caráter de sigilo ou reserva.

\section{Redes de Especialistas}

O compartilhamento e a otimização de recursos entre os usuários de computador fez surgir o conceito de rede. Segundo Freeman e Allon, redes de comunicação existem sempre que dois ou mais equipamentos de processamento de dados estejam aptos para a troca de mensagens entre si ${ }^{30}$. As mudanças nas condições econômicas, sociais e políticas, a aceleração nas mudanças científicas e tecnológicas, a necessidade de reduzir o ciclo pesquisa-desenvolvimento-produto-mercado, a necessidade de interdisciplinaridade, o esgotamento da capacidade de resposta de instituições isoladas, a necessidade de estruturas leves e ágeis levaram as instituições, empresas e entidades governamentais a se organizarem em redes cooperativas de pes- quisa no mundo inteiro. Uma rede pode ser definida como uma organização de coesão tênue de diferentes grupos ligados entre si por vínculos de natureza diversa. Redes são tipicamente centros "não-físicos", que dispõem de meios de comunicação avançados a fim de promover a interação de participantes com qualificações complementares $^{31}$. O objetivo maior para a organização das redes é reunir especialistas diversos em torno de um objetivo comum. As principais motivações para a formação de redes incluem objetivos estratégicos, preocupações de incertezas, fertilização cruzada, reduzir o ciclo de desenvolvimento do mercado, monitorar oportunidades, mudanças nas tecnologias e no ambiente, compartilhamento das competências, acesso ao mercado, posicionamento de mercado ${ }^{32}$. Tais questões devem ser acompanhadas pelas empresas para que se manterem competitivas, e este monitoramento é feito sem dúvidas mediante análise de informações estratégicas para a tomada de decisão cuja coletas é feita neste âmbito e as informações analisadas pelos especialistas, hoje na sua maioria organizados em redes. Portanto, a formação de redes é de fundamental importância para a Inteligência Competitiva, porque permite a obtenção de respostas rápidas do ambiente interno de uma organização, mas sobretudo do ambiente externo, cujo monitoramento para as empresas é indispensável para o posicionamento de mercado e vantagem competitiva.

\section{Redes de Especialistas Internos}

Será formada pelos técnicos Finep de acordo com suas especialidades, competências e experiências de trabalho.

\section{Especialistas externos}

Será formada pelos consultores, parceiros e os próprios clientes, enfim todos os consultores já constituídos pela Finep para não só dar parecer sobre seus projetos, como também em qualquer assunto que ela venha precisar. Geralmente, estes consultores encontram-se nos centros de excelência, nas universidades e institutos de pesquisas e empresas de consultoria que, na sua maioria, são clientes-Finep. A sistematização de seus dados poderá se tornar um subproduto do Sistema de Informações de Clientes para Finep.

A atual Estrutura de Informações da Finep, a sua origem e o tipo de informação em que se inserem é retratada pela figura 9, a seguir. É visível a integração de todos os elementos anteriormente elencados e suas inter-relações dentro desta atual estrutura de informações da Finep, os quais deverão ser considerados prioritariamente quando da aplicação metodológica das etapas de construção de Sistema de Informação de Clientes com base nos pressupostos da Inteligência Competitiva.

\section{CONSIDERAÇÕES FINAIS E RECOMENDAÇÕES}

O Brasil, em face da globalização, está hoje diante de um desafio: fazer da ciência e tecnologia e da atividade de P\&D a alavanca para o salto qualitativo em seu desenvolvimento, no qual a informação é um elemento vital. Por outro lado, ciência e tecnologia andam sempre juntas e são elos necessários de uma corrente que tem como objetivo o desenvolvimento econômico e social de uma nação. Nenhum destes elos existe sozinho. Trata-se das fases necessárias e interdependentes de uma macropolítica capaz de alavancar o seu macroambiente - universidades, empresas, organismos governamentais e não-governamentais.

A Finep, como principal agência de financiameno em C\&T, que, ao longo dos seus 32 anos, ajudou a consolidar o ciclo de montagem do complexo de C\&T, encontra-se também diante do mesmo desafio. Para a Finep, hoje, a informação é vital para o cumprimento de sua missão e de seu negócio.

A estruturação de um sistema de informações de clientes da Finep vai permitir o monitoramento do movimento brasileiro rumo ao desenvolvimento, uma vez que são os clientes Finep atores do próprio desenvolvimento científico e tecnológico do país. Ao mesmo tempo, as informações estratégicas serão 
geradas para a sua autogestão, permitindo: estruturar dados externos, de clientes, associando-os à posição de mercado de produtos e serviços, à infra-estrutura de P\&D, cruzar com dados internos, especialmente aqueles sobre financiamento de projetos Finep, e compará-los com outras fontes externas, resultando em um conjunto de informações com valor agregado que ajudarão a Finep também a consolidar o seu caminho por meio do conhecimento, enquanto know-how de suas competências internas e da própria informação, enquanto patrimônio acumulado ao longo de sua existência. Ao mesmo tempo o Sistema de Informações de Clientes da Finep poderá ser suporte para um Serviço de Inteligência Competitiva com a função principal de gerar informações com valor agregado que serão usadas para o planejamento estratégico e a tomada de decisão, melhorando o seu posicionamento mediante a sustentação de vantagens competitivas, fatores de diferenciação importantes neste mundo globalizado.

$E$, finalmente, podemos dizer que o Sistema de Informações para Clientes tornar-se-á não só um instrumento de apoio à tomada de decisão nos vários níveis, assegurando a redução do tempo de resposta diante das demandas do ambiente interno e externo, redução dos custos, custos evitados, aumento de receitas, valor agregado, bem como representará para a sociedade uma valiosa fonte de informação para estudos e pesquisa.

Tais benefícios oriundos de uma infraestrutura de um Serviço de Inteligência Competitiva terão impactos decisivos nas diversas áreas/processos da Finep, bem como no seu posicionamento, como principal agência governamental de financiamento em C\&T, que será mantido e fortalecido por este processo.

O Sistema de Informações para Clientes em operação e visando a cada vez mais utilizar o conhecimento e a informação como um negócio deverá ser estruturado na forma de Unidade de Inteligência Competitiva para este fim e, ao mesmo tempo, deverá ser consolidada a infra-estrutura de informa-

FIGURA 9

\section{Estrutura de Informação da Finep}

Informações Externas e Internas Armazenadas na Finep. Dados e Informações de Projetos.

\section{DADOS E INFORMAÇÕES TÉCNICAS}

- Técnico e econômico financeiro

- Parecer técnico de consultores

- Relatório técnico de análise

- Relatórios de acompanhamento

- Avaliações

- Indicadores

- Relatórios Técn icos Parciais E Finais

DADOS E INFORMAÇÕES JURÍDICAS

- Estatuto ou contrato social

- Garantias

- Condicionantes contratuais e pré-contratuais

- Convênios e contratos

\section{DADOS E INFORMAÇÕES CADASTRAIS}

\section{Clientes ${ }^{*}$}

- Pesquisadores/especialistas

- Parceiros

\section{- DADOS FINANCEIROS}

- Orçamento

- Desembolso

- Prazos (amortização e carência)

\begin{tabular}{ll} 
& DADOS SOBRE A ATUAÇÃO DA FINEP \\
\hline - & Atuação da Finep em C\&T \\
Séries históricas \\
Indicadores
\end{tabular}

\section{DADOS E INFORMAÇÕES GERENCIAIS

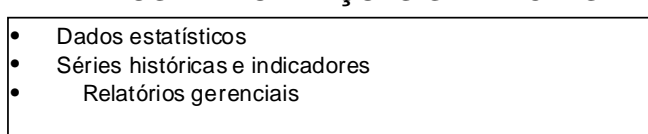

\section{ACERVO FINEP}

Planos, programas e definição de políticas governamentais

- Estado da arte e da técnica das áreas prioritárias

- Produção técnico científica da Finep

- Informações técnicas e científicas decorrente do projeto

- Relatórios parciais e finais de projeto

- Estudos setoriais

Análise Técnica do Projeto
INFORMAÇÕES EXTERNAS

\begin{tabular}{|l|}
\hline Bancos de dados \\
nacionais e \\
internacionais \\
\\
Informação \\
científica e \\
tecnológicas \\
\\
Dados estatísticos \\
séries históricas e \\
indicadores de C\&T \\
\\
Informações \\
normativas e \\
jurídicas \\
\\
Informações \\
bibliográficas \\
Dados cadastrais: \\
clientes, redes de \\
especialistas, \\
parceiros \\
Internet \\
Patentes \\
\end{tabular}


ção já disponível e em uso, fortalecendo o Sistema de Informações Corporativas da Empresa, no qual está registrado a memória da Finep em C\&T, e que representa parte da memória nacional em ciência e tecnologia.

Os elementos da Inteligência Competitiva se integram completamente na construção do Sistema de Informação de Clientes, que, uma vez em operação, passa a ser uma das ferramentas para o Sistema de Inteligência Competitiva para a Finep, conforme demonstra a figura 10, a seguir.

\section{FIGURA 10}

Integração dos elementos de inteligência competitiva na construção do sistema de informação do cliente

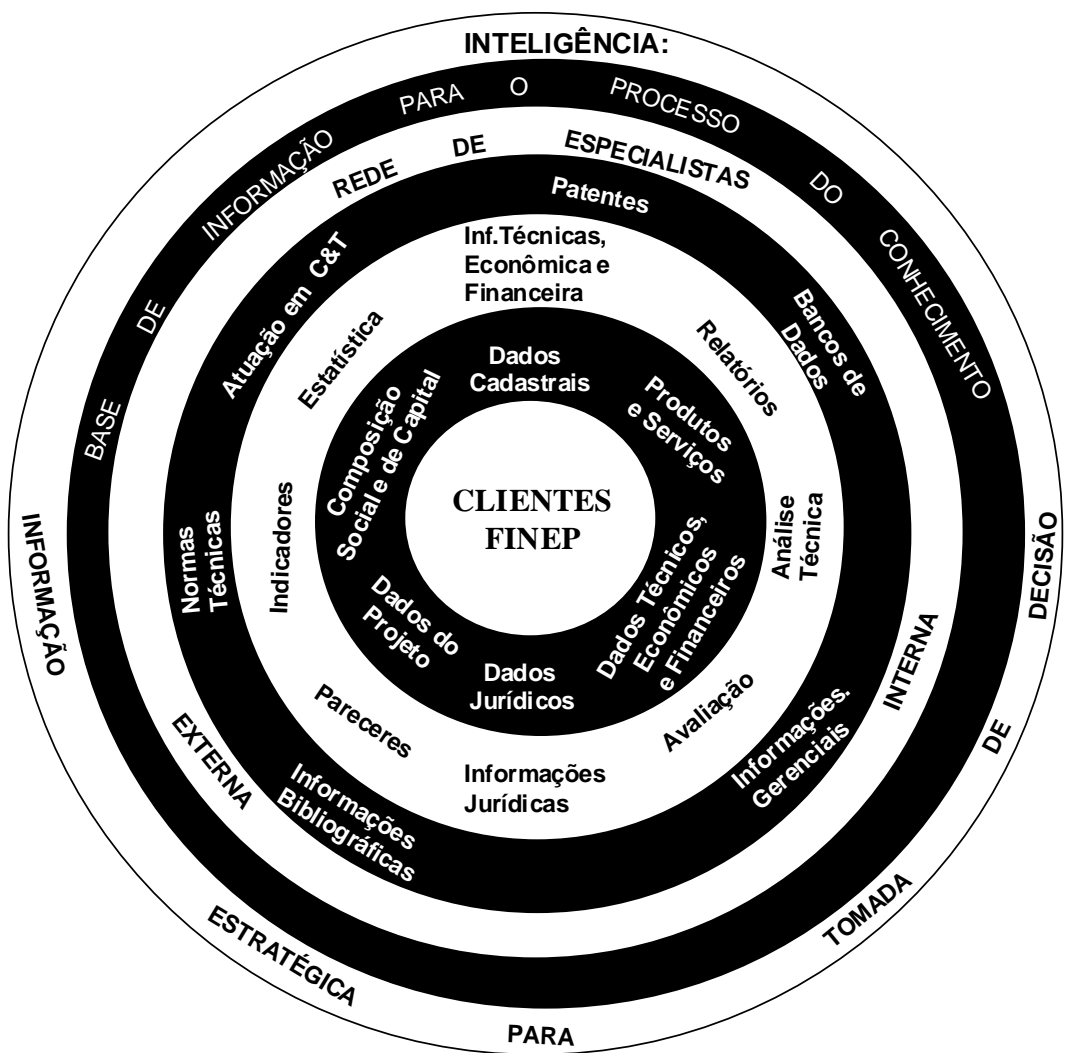

\section{REFERÊNCIAS BIBLIOGRÁFICAS}

Conforme nota de rodapé no 1 este artigo foi extraído do trabalho:

BATTAGLIA, Maria da Glória Botêlho. L' Intelligence Compétitive comme support pour la construction d' un modèle de Système d'Information des Clients pour la FINEP. Rio de Janeiro / Marseille, CEIC / DEA. Mémoire en vue de l'obtention du Diplome d'Etudes Approfondies DEA.,1998.

1. PINHEIRO, Lena Vânia Ribeiro. A Ciência da Informação entre sombras e luz: domínio epistemológico e campo interdisciplinar. Rio de Janeiro, UFRJ/ ECO - DEP/IBICT, 1992, Tese.

2. AGUIAR, AFRÂNIO CARVALHO. Informacão e atividades de desenvolvimento científico, tecnológico e industrial: tipologia proposta com base em análise funcional. IN:Ci.Inf.,Brasília,20 (1):715,jan./jun.1991.

3. MAUTORT, apud.

AGUIAR, AFRÂNIO CARVALHO. Informação e atividades de desenvolvimento científico, tecnológico e industrial: tipologia proposta com base em análise funcional. IN:Ci.Inf.,Brasília,20 (1):715,jan./jun.1991
4. LONGO, Waldemir Pirró. Inovação e Gestão Tecnológica. IN: Curso de especialização em inovação e gestão tecnológica. Rio de Janeiro, FINEP, 1997.

5. PINHEIRO, Lena Vânia R. Informação e Desenvolvimento. Rio de Janeiro, IBICT,19... . 17p. Seminário IBICT.

6. MIRANDA, A. A política de transferência de informação: uma abordagem preliminar. IN: Congresso Latino-Americano de Biblioteconomia e Documentação,1 Salvador, p. 21-26, set., 1980 .

7. MENOU, M.J., apud.

FIGUEIREDEO, Nice Menezes. Informação como ferramenta para o desenvolvimento. Ci. Inf., Brasília, 19(2):123-29, jul./dez., 1990

8. FIGUEIREDEO, Nice Menezes. Informação como ferramenta para o desenvolvimento. Ci. Inf., Brasília, 19(2):123-29, jul./dez., 1990

9. PEARSON, A. W., apud.

FIGUEIREDEO, Nice Menezes. Informação como ferramenta para o desenvolvimento. Ci. Inf., Brasília, 19(2):123-29, jul./dez., 1990. 


\section{BORKO, apud.}

BATTAGLIA, Maria da Glória Botelho. Análise sistêmico documental e proposta de um sistema em C\&T para a Finep. Rio de Janeiro, UFRJ/ECO - DEP/IBICT, Dis.,1992.

11. LONGO, Waldemir Pirró e. Tecnologia e transferência de tecnologia. Rio de janeiro, $(19 \ldots \quad) 1 \mathrm{v}$.

12. CASTOR, Belmiro Valverde Jobim. Tecnologia apropriada: uma proposta de critérios de avaliação e sua aplicação. Rio de Janeiro, Revista de Administração. V.18,nํ‥2, p.40-47, abr./jun.1983.

13. SANTOS, Raimundo N. Macedo dos. Propriedade industrial e monitoramento tecnológico. IN: Curso de especialização em inteligência competitiva. Rio de Janeiro, MCT/INT, CNPq/IBICT, UFRJ/ECO, 1997

14. CABRAL, Ubirajara Quaranta. Propriedade industrial. IN: Curso de especialização em inteligência competitiva. Rio de Janeiro, MCT/INT, CNPq/IBICT, UFRJ/ECO, 1997.

15. FEDERAÇÃO INTERNACIONAL DE DOCUMENTAÇÃO, apud.

AGUIAR, AFRÂNIO CARVALHO. Informação $e$ atividades de desenvolvimento científico, tecnológico e industrial: tipologia proposta com base em análise funcional. IN:Ci.Inf.,Brasília,20 (1):7-15,jan./ jun.1991.

\section{Competitive Intelligence fashioning: the client information system}

\begin{abstract}
FINEP business is supporting Science and Technology as the tools for building the future of Brazil, therefore it demands na information system modelled to attending, both, his customers loking for investment and the technicians responsibles for the scientific and technologic development, from where are emerging the new financing demands. This article present a $n$ Information System for Customers -FINEP shaped in the Competitive Intelligence components in order to allowing FINEP to move through data-intensive enviroment and targeting the investment in science and technology acording to the strategies of the competitve arena, nowadays. The Information System will yield FINEP toward a dedicated office inside the company and enhancing its goals.
\end{abstract}

\section{Keywords}

Agency for the Financing of Studies and Projects - Finep; Information system; Clients' information system; Competitive intelligence; Clients-Finep.
16. KLINTOE, Kjeld, apud.

AGUIAR, AFRÂNIO CARVALHO. Informação e atividades de desenvolvimento científico, tecnológico e industrial: tipologia proposta com base em análise funcional. IN:Ci.Inf.,Brasília,20 (1):715,jan./jun.1991.

17. PORTER, Michael E. Estratégia competitiva: Técnicas para análise de indústrias e da concorrência. Trad. de Elizabeth Maria de Pinto Braga. $7^{\underline{a}}$ ed., Campus, Rio de Janeiro, 1991

18. GUINCHAT, Claire \& MENOU, Michel. Introdução geral às ciências e técnicas da informação e documentação. Trad. Míriam Vieira da Cunha. Brasília, IBICT,1994.

19. BID. Oficina de Evaluación (EVO). Evaluación: Una herramienta de gestión para mejorar el desempeño de los proyetos. BID, Washington, 1997.

20. PINHEIRO, Lena Vânia Ribeiro. Sistemas de Informação. IN: Curso de especialização em inteligência competitiva. Rio de Janeiro, MCT/INT, CNPq/IBICT, UFRJ/ECO, 1997.

21. STOLLENWERK, Maria Fátima Ludovico. Gestão Estratégica e Inteligência Tecnológica: Concepção e Desenvolvimento de um Sistema de Inteligência Tecnológica em uma Empresa de Petróleo. Rio de Janeiro / Marseille, CRRM / PETROBRÁS. Diss. 1997.

22. CAPRA, F. O tao da física. São Paulo: Cultrix,1988. 1v

23. BARTALANFFY, Ludwig von. The theorrrry of open systems in Fhysics and Biology. Science,v.111,p.23-29, 1950.

24. ROCKART, apud.

STOLLENWERK, Maria Fátima Ludovico. Gestão Estratégica e Inteligência Tecnológica: Concepção e Desenvolvimento de um Sistema de Inteligência Tecnológica em uma Empresa de Petróleo. Rio de Janeiro / Marseille, CRRM / PETROBRÁS. Diss. 1997.

25. Tayson.........

26. DOU, Henri. Veille Technologique et compétitivité: L'intelligence économique au service du développement industriel. Paris, Dunod,1995.

27. FULD, Leonard M. The new competitor intelligence. Jonh Willey \& Sons,Inc., 1996.

28. JAKOBIAK, François. Que sais-je? Information scientifique et technique. Paris, Presses Universitaire de France, 1995

29. TOFFLER, Alvin: TOFFLER, Heidi. Powershilt: as mudanças do poder. Rio de Janeiro: Record, 1990. $613 \mathrm{p}$.

30. FREEMAN,C. L. \& ALLON, E. apud. FERREIRA, Sueli Mara Soares Pinto. In- trodução às redes eletrônicas de comunicação. C.Inf. Brasília,v.23,n.2,p.258263, maio/ago.1994.

31 WEISZ,J. \& ROCO, M. C. Redes de pesquisa e Educação em Engenharia nas Américas. Mimeo, [s.d]

32. WEISZ, J. \& ROCO, M. C. apud.

LASTRES, Helena M.M. Inovação e o nove paradigma das tecnologias de informação. Notas de curso, Escola de pós-graduação em Ciência da Informação da UFRJ, Mimeo, Rio de Janeiro, 1995 .

33. TAPSCOTT, Don. Mudança de Paradigma. São Paulo, Makron Books, 1995.

34. DRUCKER, Peter F. The coming of the new organization. Harvard Bisiness Review. Boston. V.88. n.1. p.45-53. Jan./Feb. 1988.

35. SAMPER, J. Philip. Senior managemente commitement: Eastman Kodak's policy on the use os information (market intelligence system). Planing Review, Oxford, v.19, n.2, p. 47, Mar./apr., 1991

36. GILAD, Benjamin. The role of organized competitive intelligence in corporate strategy. The Columbia Journal of Word Business. New York, v.24, n.4, p.2935.1989 .

\section{Maria da Glória Botelho Battaglia}

MSc em Ciência da Informação; DEA em Inteligência Competitiva; técnica da Financiadora de Estudos e projetos (Finep)

E-mail: bataglia@finep.gov.br 